\title{
Epidemiology and associated factors of migraine headache among iranian medical students: A descriptive-analytical study
}

\author{
Kourosh Zarea $^{\mathrm{a}, *}$, Mahnaz Rahmani $^{\mathrm{b}}$, Fatemeh Hassani ${ }^{\mathrm{c}}$, Ashrafalsadat Hakim $^{\mathrm{a}}$ \\ a Nursing Care Research Center in Chronic Diseases, Ahvaz Jundishapur University of Medical Sciences, Ahvaz, Iran \\ b Student Research Committee, Ahvaz Jundishapur University of Medical Sciences, Ahvaz, Iran \\ c Emam Khomaini Hospital, Ahvaz Jundishapur University of Medical Sciences, Ahvaz, Iran
}

\section{A R T I C L E IN F O}

\section{Article history:}

Received 5 September 2017

Accepted 4 October 2017

Available online 20 October 2017

\section{Keywords:}

Headache

Migraine disorder

Medical students

\begin{abstract}
A B S T R A C T
Introduction: High incidence of migraine has caused to categorize it as one of the most debilitating human diseases. This study aims to investigate the incidence of migraine headache and the factors associated with it among medical students.

Methodology: The present research is a descriptive, cross-sectional study. The sample size includes 390 subjects that were selected through proportionate stratified random sampling. To this purpose we used a questionnaire that was designed according to international headache standards criteria. Data was analyzed by SPSS. Accordingly, chi-square, independent $t$-test, and logistic regression were used for evaluation of clinical data.

Results: In the finding it was reviled that 318 subjects out of 390 participants in the study had experienced headache (81.53\%). In total, 27 subjects (6.9\%) were suffering from migraine including $77.8 \%$ women and $22.2 \%$ men. The most common complication of migraine headache is dizziness by $17.2 \%$. Factors intensifying migraine headaches include stress (63\%), sunlight or fluorescent light (55.6\%), loud noise (48.1\%), fatigue (77.8\%), and overheating (51.9\%).

Conclusion: among the factors affecting the intensification of migraine headaches, stress, sunlight, noise, fatigue, heat, menstruation in women, too much work, late sleep at night and some foods such as fish, caffeine, pepper, fat and fried foods were also identified as the food factors intensifying migraine headaches. Since the students of medical sciences are a part of health care system and such headaches will reduce their efficiency in health care delivery. Socio-economic impact of migraine on quality of life of student considerable and must be emphasized in health-treatment programs and plans.
\end{abstract}

(C) 2017 Published by Elsevier, a division of RELX India, Pvt. Ltd on behalf of INDIACLEN.

\section{Introduction}

Headache is one of the most common symptoms experienced and more than $90 \%$ of people experience a headache at least once per year; therefore,successful headache management is considered as a major goal in health interventions. ${ }^{1}$ Migraine is a complex neurovascular, genetically transmitted disorder characterized by brain sensory hyperexcitability. ${ }^{2}$ It is associated with nausea, vomiting, and loss of appetite. Most people suffering from

\footnotetext{
* Corresponding author at: Nursing Care Research Center in Chronic Diseases, Nursing and Midwifery School, Nursing Department, Ahvaz Jundishapur University of Medical Sciences, Ahvaz, Iran. Tel.: +9 833738622.

E-mail addresses: Zarea_k@ajums.ac.ir, Kourosh1685@gmail.com (K. Zarea), mahnaz.rahmani90@gmail.com (M. Rahmani), fatemeh.hassani1187@gmail.com (F. Hassani), hakim3448200@yahoo.com (A. Hakim).
}

migraine report that their work and family relations have been negatively affected by migraine attacks. ${ }^{3}$

According to National Health Foundation, each year 28 million Americans suffer from migraine headaches. In addition, the annual cost of treatment and individuals' being absent due to headache is about 50 billion dollars. ${ }^{4}$ According to WHO report, the incidence of migraine in America and Europe in adults was estimated about $10-15 \%$ per year. ${ }^{5}$ The ratio of incidence in women since the age of 10 years and during the childbearing ages is more than that of the men. ${ }^{6}$ According to a study in 2007 in Iran, 8.1\% of the students were suffering from migraine headache, and it was more common among the single students. ${ }^{7}$

The review of clinical scales shows that migraine sufferers are more vulnerable to the life adversities. ${ }^{8}$ Most patients with migraine headache are worried, anxious and obsessive. Such concerns and anxiety lead to hiding the feelings and the onset of headache, and chronic headache and lack of attention to 
personality traits of individuals can be changes into migraine headaches. ${ }^{9}$ Migraine headache in adults causes absenteeism in the workplace and imposes high treatment costs. In a study conducted on dental students in India the migraine incidence was reported as $13.4 \%$, and $87.5 \%$ of it was associated with women with majority of self-medication. ${ }^{10}$ In another study conducted on medical students in Kuwait the incidence of migraine in the last two years of study significantly increased from $21 \%$ to $44 \%$ in comparison to the first five years and according to the students, the intensifying factors were introduced as stress (24\%), irregular sleep (20.8\%), and over study (18.5\%). The results showed that the incidence, frequency, and severity of headaches would increase in the last two years of study. ${ }^{11}$ The incidence of migraine in medical students in Iran (2012) was $14.2 \%$ and tension type headache was $44.2 \%$. Positive family history was observed in $9.5 \%$ of the students suffering from headaches. The results showed that the incidence of headache was high in medical students and social, economic factors and several years of study could be some important factors in headache incidence. It is necessary to carry out more multicenter studies at medical universities of the country. ${ }^{12}$

In the study carried out by Ghorbani, family positive history was found in $9.5 \%$ of students with headache. The lower socioeconomic status, year of study (3rd and 5th year students), was seemed to had higher prevalence in students with headache. headache and concomitant disease was not significantly different. ${ }^{13}$ The comparison of the figures with other studies in different countries and other groups of society leads to the conclusion that the incidence of migraine among the medical students and doctors in our country is nearly one and a half or twice as much as the total population. ${ }^{14}$

These headaches can have great negative effects on individuals' performance, and high costs are imposed on society due to absenteeism in the workplace as well as education and treatment of such people. ${ }^{15}$ A large percentage of migraine patients have psychological problems such as depression and anxiety disorders. ${ }^{16}$ Moreover, this disease affects individual, family, social, and economic aspects of the patient's life and on the other hand exerts very high costs on treatment and health sector. Given the above points and since the students are scientific and national pillars of the society, and economic, social health of the community emanates from mental and occupational health of these people (particularly the groups associated with medical science branches), the necessity of conducting this study among medical students is quite justified. This study aimed to investigate the incidence of migraine headaches and its associated factors from the perspective of the Medical students at a University of south of Iran to assess the present conditions for future therapeutic interventions and to reduce damage to both individuals and community through the attempts to prevent or reduce such attacks.

\section{Materials and methods}

\subsection{Study design}

This is a descriptive and cross-sectional study which was carried out among the students at Ahvaz Jundishapur University of Medical Sciences, South of Iran in 2016.

\subsection{Subjects}

The samples were selected trough proportionate stratified random sampling (each faculty one category) and the samples were collected from each faculty in proportion with the size of the students. The researcher collected the data related to all the students studying at different levels separately and in terms of their major and gender and identified the number of required samples from each faculty with regard to the number of male and female students at each faculty. Then, the researcher attended the classed, introduced himself, and expressed the objective, importance and method of the research. According to the formula, the sample size was determined as 342 subjects and considering the probable lost, 390 subjects ultimately participated in the study through stratified random sampling. The data were collected through the distributed questionnaires among the students.

Study inclusion criteria included being the student of Ahvaz University of Medical Sciences, age of 18-40 years, desire to participate in the study, and lack of concomitant underlying diseases and the exclusion criterion was incomplete response to all the questionnaire items. According to the criteria of international headache society (IHS), migraine diagnosis included at least five attacks with the following features: the headache attacks must last 4-72 h (untreated or unsuccessfully treated). The headache must have at least 2 of the following features: a. unilateral, b. pulsating, c. moderate to severe and interfere with doing daily routine activities, d. gets worse or intensified by doing daily routine activities or walking up or down the stairs. During the headache, there should at least be one of the following features: nausea, vomiting and photophobia.

\subsection{Measurements}

The questionnaire was designed by the researcher according to the international headache standards (IHS) and consultation with a headache specialist neurologist, and contained individual's demographic information, headache characteristics if any and the factors associated with headache. It was completed by the samples. Content validity was used to measure the scientific validity of the questionnaire. The correlation coefficient of the applied tool was calculated through test-retest method which was equal to 0.89 .

In this study, only the samples completely fulfilling the criteria of International Headache Society (IHS) and also the secondary causes were denied according to the clinical examination of the samples. The rest of group complaining from headache were nonclassified and in a general term were categorized as "the others".

\subsection{Ethical consideration}

In this study to adhere ethical considerations, researcher obtain permission from Research Ethic Committee with code ajums. REC.1393.200. Also, researcher got informed consent from subjects before data gathering.

\subsection{Statistical analysis}

After collecting the data, they were analyzed using SPSS software. Descriptive statistics, relative frequency, absolute frequency, mean, and standard deviation were used for evaluation and specification of research sample and chi-square test, independent $t$-test, and logistic regression were used for evaluation of clinical data.

\section{Results}

In this study, results showed that $59.7 \%$ of the samples were between the ages of $18-22.146$ men (37.43\%) and 244 women (62.56\%) participated in the research. $90 \%$ of the participants were single and $10 \%$ were married.

On the whole, 318 subjects out of 390 participants in the study had experienced the headache $(81.53 \%)$. The frequency of headache was once a month in $43.8 \%$ of the participants, once a week in $21.3 \%, 2-4$ times a week in $9.2 \%$, every day in $2.6 \%$ and in 
$4.6 \%$ of the participants the frequency was variable. 300 students (76.9\%) suffering from headache, had referred to a specialist to recognize the cause of headache.

In total, 27 subjects (6.9\%) were suffering from migraine including $77.8 \%$ women and $22.2 \%$ men. The duration of headache attacks in 10.85 of cases was less than $30 \mathrm{~min}$, in $10.18 \% 30$ to $60 \mathrm{~min}$, in $18.7 \% 1$ to $2 \mathrm{~h}$, in $10 \% 3$ to $6 \mathrm{~h}$, in $3 \% 6$ to $25 \mathrm{~h}$ and only in $1 \%$ of cases the headache lasted several days. In $25.9 \%$ of all participants in the research unilateral headache and in $28.5 \%$ of them unilateral headache has been reported. In $17 \%$ of the participants, headache began from the eyes, in $23 \%$ from the forehead, and in $16.9 \%$ from the temple and the pain mainly continued in the same places. In $17.7 \%$ of cases the headache was reported as throbbing, in $19.7 \%$ as tension, in $13.3 \%$ as radiating, and in the rest as vague (Table 1 ).

The most common associated symptoms of headache are vertigo (17.2\%), photophobia (13.1\%), nausea and vomiting (11.8\%). $46.7 \%$ of the participants stated that doing daily activities intensified their headaches and $17.9 \%$ complained that headache often prevented them from doing their daily activities. In $49.4 \%$ of the participants warning signs were reported the most common of which were anorexia (10.5\%), decreased vision (9.7\%), loss of consciousness (8.2\%), and weakness of limbs (7.9\%). $7.5 \%$ of the subjects spent fewer than 3 days a week without headache. The average age of the subjects with migraine headache was 24.1 and without migraine headache was 22.6 years. 17 (63\%) participants with migraine headaches had visited a doctor and brain imaging had been done only for two patients. $40.7 \%$ of them were using painkillers to alleviate their headaches. In $51.9 \%$ of cases, headache had caused no problem during the sleep. In $41.7 \%$ sometimes and in $7.4 \%$ often the headache had wakened them up during the night. In $85.2 \%$ of the participants with migraine headaches positive family history was mentioned that included immediate relatives in $63 \%$ of cases. $96.3 \%$ of the subjects reported no history of injury to head or neck, suffering from chronic diseases or smoking so far (Table 2).

Some sufferers mentioned some factors as headache intensifying factors the highest of which included stress (63\%), sunlight or florescent light (55.6\%), loud noise (48.1\%), fatigue (77.8\%), smells like cigarette smoke or perfume odor (37\%), overheating (51.9\%), watching TV or computer monitor (37\%), while the role of air travel, cold weather, smoking, and exercise in intensifying the headache of such people was less than $10 \%$ (Table 3 ). Sleep pattern changes such as insomnia at night (25.9\%), working too much and sleeping late at night (40.7\%), oversleeping (11.1\%), and poor sleep and frequent awakening during the night (29.6\%) have been reported in patients with migraine headache symptoms (Table 3 ). Diet pattern changes such as elimination of meals (18.5\%), irregular eating, eating without regular time (40.7\%), overeating, excessive eating (18.5\%), and anorexia (22.2\%) (Table 3). In case of women, menstruation had the highest effect on intensifying migraine headaches (55.6\%) and pregnancy and contraceptive pills or other hormones had no significant effects on intensifying migraine headaches (Table 3 ). $74.1 \%$ of the participants were sleeping $6-8 \mathrm{~h}$ per day in average. According to the individuals' experiences, fatty and fried foods (33.3\%), pepper (25.9\%), nuts (walnut, peanut, pistachio, nut, etc.), caffeine, fish, and tuna (14.8\% each), high fat dairy products, red meat and canned food ( $11.1 \%$ each) intensified migraine headache, and the role of each one of the foods like low fat dairy, poultry (chicken), citrus fruits, sweets, vegetables and fruits, alcoholic beverages, egg, legumes, chocolate, and cocoa was less than $10 \%$ (Table 3 ). Among the stated factors that intensify migraine headaches, through the use of logistic regression test and with regard to the obtained $p$-value, age and sunlight and florescent light were identified as the main intensifying factors and the chance ratio for them is 1.138 and 0.315 respectively, and factors such as stress, noise, fatigue, heat, late sleep, menstruation in women, certain foods (like fish, legumes, caffeine, fried foods, pepper) and positive family history were in the next grade and associated with the two main factors.

\section{Discussion}

The aim of this study was to investigate the epidemiology of migraine headaches and the related factors among the students of medical sciences. The results of the study indicate the higher incidence of migraine headache in women compared with men. The results were in line with the findings of other studies in this field. ${ }^{17-20}$ The incidence of migraine is $6.9 \%$ and in the other Iranian research conducted on students, migraine incidence is reported as $7.14 \%$. On the contrary, in a research conducted in India (2013) on medical students, migraine incidence was $44 \%^{21}$ and in The U.S. (2014) it was reported as $24 \%$ that can result from geographic and racial differences. Unlike the present research, no significant difference was observed in Zahedan, Iran in terms of gender

Table 1

Relative frequency distribution of the sample according to demographic variables associated.

\begin{tabular}{|c|c|c|c|c|}
\hline & & Migraine N(\%) & NO Migraine N(\%) & P Value \\
\hline \multirow[t]{2}{*}{ Sex } & Female & $21(77.8)$ & $223(61.4)$ & 0.09 \\
\hline & Male & $6(22.2)$ & $140(38.6)$ & \\
\hline \multirow[t]{2}{*}{ Marital status } & Single & $23(85.2)$ & $329(90.6)$ & 0.35 \\
\hline & married & $4(14.8)$ & $34(9.4)$ & \\
\hline \multirow[t]{3}{*}{ Degree } & expert & $13(48.1)$ & $164(45.2)$ & 0.27 \\
\hline & Master degree & $5(18.5)$ & $36(9.9)$ & \\
\hline & $\mathrm{PhD}$ & $9(33.3)$ & $163(44.9)$ & \\
\hline \multirow[t]{2}{*}{ Interest in the field of education } & Yes & $26(96.3)$ & $329(90.6)$ & 0.32 \\
\hline & No & $1(3.7)$ & $34(9.4)$ & \\
\hline \multirow[t]{2}{*}{ Employment status } & Practitioner & $4(14.8)$ & $40(11)$ & 0.54 \\
\hline & Unemployed & $23(85.2)$ & $323(89)$ & \\
\hline \multirow[t]{7}{*}{ Ethnicity } & Fars & $11(40.7)$ & $98(27)$ & 0.22 \\
\hline & Bakhtiari & $7(25.9)$ & $84(23.1)$ & \\
\hline & Lor & $7(25.9)$ & $88(24.2)$ & \\
\hline & Kurdish & $0(0.00)$ & $25(6.9)$ & \\
\hline & Turkish & $2(7.4)$ & $15(4.1)$ & \\
\hline & Arabic & $0(0.00)$ & $40(11)$ & \\
\hline & Other & $0(0.00)$ & $13(3.6)$ & \\
\hline Age & mean \pm SD & $24.1 \pm 5.18$ & $22.6 \pm 3.58$ & 0.044 \\
\hline The work experience & & $1.29 \pm 3.77$ & $0.47 \pm 1.98$ & 0.056 \\
\hline
\end{tabular}

"Significant level was 0.05 . 
Table 2

The relative frequency distribution of the sample according to some local variables with the presence or absence of migraine.

\begin{tabular}{|c|c|c|c|c|}
\hline Characteristics & & Migraine $\mathrm{N}(\%)$ & NO Migraine $\mathrm{N}(\%)$ & P Value \\
\hline \multirow[t]{3}{*}{ Waking from sleep due to headaches } & never & 14(51.9) & $321(88.4)$ & 0.00 \\
\hline & Some time & $11(40.7)$ & $40(11)$ & \\
\hline & most & $2(7.4)$ & $2(0.6)$ & \\
\hline \multirow[t]{2}{*}{ Family history of headache } & Yes & $4(14.8)$ & $213(60)$ & 0.00 \\
\hline & No & $23(85.2)$ & $150(40)$ & \\
\hline \multirow[t]{2}{*}{ Smoking } & Yes & $1(3.7)$ & $17(4.7)$ & 0.81 \\
\hline & No & $26(96.3)$ & $346(95.3)$ & \\
\hline \multirow[t]{2}{*}{ History of trauma to the head or neck } & Yes & $1(3.7)$ & $24(6.6)$ & 0.55 \\
\hline & No & $26(96.3)$ & $339(93.4)$ & \\
\hline History of chronic disease & Yes & $1(3.7)$ & $16(4.4)$ & 0.86 \\
\hline
\end{tabular}

"Significant level was 0.05 .

Table 3

Incidence of triggering Factors of migraine among medical Students.

\begin{tabular}{|c|c|c|}
\hline Triggering factors & Number (\%) & P Value \\
\hline Stress & $17(63)$ & 0.02 \\
\hline Sunlight & $15(55.6)$ & 0.00 \\
\hline Medications & $0(0.00)$ & 0.78 \\
\hline Air travel & $2(7.4)$ & 0.222 \\
\hline Noise & $13(48.1)$ & 0.006 \\
\hline Fatigue & $21(77.8)$ & 0.001 \\
\hline Odors (smoke, or the smell of perfume) & $10(37)$ & 0.1 \\
\hline Overheating & $14(51.9)$ & 0.00 \\
\hline Cold weather & $2(7.4)$ & 0.61 \\
\hline Smoking & $0(0.00)$ & 0.63 \\
\hline Sport & $2(7.4)$ & 0.222 \\
\hline Study & $5(18.5)$ & 0.90 \\
\hline Watching TV or monitor & $10(37)$ & 0.08 \\
\hline Sleepless Night & $7(25.9)$ & 0.228 \\
\hline Hard work and sleep late at night & $11(40.7)$ & 0.02 \\
\hline Sleeping & $3(11.1)$ & 0.80 \\
\hline Bad sleep (waking frequently during the night) & $8(29.6)$ & 0.111 \\
\hline Remove meals & $5(18.5)$ & 0.08 \\
\hline Irregular eating & $11(40.7)$ & 0.05 \\
\hline Overeating & $5(18.5)$ & 0.80 \\
\hline Anorexia & $6(22.2)$ & 0.22 \\
\hline Menstrual period & $15(55.6)$ & 0.001 \\
\hline Pregnancy & $0(0.00)$ & 0.699 \\
\hline Birth control pills & $0(0.00)$ & 0.539 \\
\hline Other hormonal medicines & $1(3.7)$ & 0.152 \\
\hline High-fat dairy & $3(11.1)$ & 0.76 \\
\hline Low-fat dairy & $1(3.7)$ & 0.61 \\
\hline Red meat & $3(11.1)$ & 0.144 \\
\hline Poultry (chicken and chicken) & $1(3.7)$ & 0.34 \\
\hline Citrus & $0(0.00)$ & 0.69 \\
\hline Fish and canned tuna & $4(14.8)$ & 0.009 \\
\hline Pastry & $2(7.4)$ & 0.96 \\
\hline Nuts (walnut-almond, etc.) & $4(14.8)$ & 0.21 \\
\hline Vegetables & $1(3.7)$ & 0.61 \\
\hline Non-citrus fruits & $1(3.7)$ & 0.152 \\
\hline Alcohol & $1(3.7)$ & 0.34 \\
\hline Egg & $1(3.7)$ & 0.24 \\
\hline Bean & $1(3.7)$ & 0.00 \\
\hline Cans & $3(11.1)$ & 0.119 \\
\hline Caffeine & $4(14.8)$ & 0.024 \\
\hline Fatty foods and fries & $9(33.3)$ & 0.004 \\
\hline Pepper & $7(25.9)$ & 0.00 \\
\hline Chocolate and cocoa & $1(3.7)$ & 0.974 \\
\hline
\end{tabular}

"Significant level was 0.05 .

variable. ${ }^{23}$ International studies showed that there was a significant difference in terms of gender and positive family history, and the incidence of migraine in female and male students. ${ }^{24,25}$ In this research, the most common associated symptoms of headache are vertigo, photophobia, nausea and vomiting, but in the study conducted by Momayezi et al. in Yazd, the most common factors were reported as nausea (55.6\%), vomiting (40.7\%), and photophobia (85.2\%) which are significantly different from the present study. ${ }^{26}$ The research conducted by Adoukonou et al in Africa family history was $14.6 \%$ and in a study conducted in India on dental students it was reported as $20.1 \%{ }^{1,10,24} 63 \%$ of the participants with migraine headaches in this study had visited a doctor and only $40.7 \%$ of them were using painkillers while in Ardebil (2004), $62.2 \%$ of the students with migraine never went to a doctor and had just taken common painkillers for treatment that indicates the improvement of awareness in this regard among the student community of our country. On the contrary, in a study in India (2013), only $11 \%$ of the students had visited the specialist. A quarter of the samples took painkillers as self-medication. $30 \%$ of them attributed their headaches to stress and only $6 \%$ allocated it to migraine. ${ }^{21}$ In this case, cultural differences or low education could made them. In a research in Isfahan, a significant difference was observed among medical students in terms of gender and social and economic status and the incidence of migraine headache were observed more in women (in terms of gender variable) or in low social and economic status. ${ }^{12}$

In this study, among the factors affecting the intensification of migraine headaches, stress, sunlight, noise, fatigue, heat, menstruation in women, too much work, late sleep at night were significant and were consistent with other studies. ${ }^{10,12,23,27,28}$ For instance, in a research conducted on medical students in Peshawar, Pakistan (2012) the factors that had the highest effect on the intensification of migraine were stress (93.5\%), noise (74.5\%), sleep pattern change (62.5\%), elimination of meals (60\%), fatigue (53.5\%), physical activity (50\%), bright lights (48\%), caffeine (41\%), cheese (32\%), smells (32\%), and chocolate (25\%). ${ }^{29}$ Moreover, in the study conducted by Safavi et al. on the relationship between migraine headaches and women lifestyles, the results showed that there was a significant relationship between the incidence of migraine headache and some aspects of lifestyle such as nutrition and eating habits, sleep and rest pattern, patterns and habit of taking drug, but there was no significant difference between the incidence of migraine headache and smoking, pattern of physical activity and sports, and exposure to life stressors. ${ }^{30}$ In a research on students in Zahedan city, Iran, the intensifying factors of migraine were reported as stress (73\%), insomnia (52.5\%), over study (39\%), and fasting (39\%) respectively. Moreover, there was a significant relationship between the incidence of migraine and academic years, so that at higher academic years the incidence of migraine increased. ${ }^{23}$ The relationship was not significant in the present study and more research is required to prove it. Asadnia et al. showed in their study that people who do not have a good quality of sleep experience more migraine headaches and sleep problems during their lives. ${ }^{31}$ In the present study, the item of sleeping late at night was significant and is consistent with the findings of Seyed Ali et al. in Zanjan city, Iran. ${ }^{32}$ 
In case of women in this study, menstruation had the highest effect on intensifying migraine headaches (55.6\%) and pregnancy and contraceptive pills or other hormones had no significant effects on intensifying migraine headaches. McGregor et al. showed that as the level of estrogen decreased, migraine attacks would increase and conversely, as the level of estrogen increased, migraine attacks would decrease. In fact, estrogen plays a protective role in this regard. ${ }^{33}$ This could be one of the reasons of the higher incidence of migraine attacks in women.

In this research some foods such as fish, legumes, caffeine, pepper, fat and fried foods were also identified as the food factors intensifying migraine headaches. A research conducted by Avijgan in Australia confirmed it. ${ }^{34}$ However, in a research in Khoram Abad, $31 \%$ of the participants stated that some foods were effective in the intensification of headache and $45 \%$ of the participant stated that they were not effective. ${ }^{35}$ Other study showed that knowing and avoiding the foods that are effective in the intensification of migraine headaches could have a positive and decreasing effect on taking pain relievers, headaches duration, and the number of migraine attacks. ${ }^{36}$ Millichap (2003) and Taylor (2009) reviewed the food factors, list of foods and beverages affecting migraine and stated that cheese, chocolate, citrus fruits, hot dogs, foods containing monosodium glutamate, aspartame, fatty foods, ice cream, regardless of caffeine and alcohol, can aggravate migraine headaches. Moreover, foods containing tyramine, phenyl ethylamine, histamine, nitrites and sulfites can be involved in the incidence of unbearable headaches and should be restricted. ${ }^{37,38}$ In another study it was showed that the role of vitamin D in the treatment of migraine was reviewed according to previous studies and the research indicated the role of vitamin $D$ in the treatment of the number and duration of headache attacks such as migraine. However, due to few studies, more studies are needed in this regard. ${ }^{39}$ The limitations of this study included sample size, in terms of both the students who were participated and the facilities that were used, which thereby limited the general applicability of the results.

\section{Conclusion}

By conducting this study, the epidemiological data on the type and quality of headache in medical students, family history, a visit to a doctor, associated factors, and aggravating factors of migraine headaches were obtained. Since the students are a part of health care system and such headaches will reduce their efficiency in health care delivery, it is necessary to carry out studies to identify risk factors causing headache and to promote knowledge, performance and attitude towards them. Socio-economic impacts of migraine on quality of life of patients and the community are considerable and must be emphasized in health promotion programs. Conducting this study on other social groups such as adolescents, etc. could be of great importance. Furthermore, doing some studies on the prevention, reduction, and control of migraine headaches with regard to intensifying factors can be helpful.

\section{Conflicts of interest}

There no any conflict of interest between authors.

\section{Acknowledgements}

This work was financially supported by grant: (92S81) and ethical code: ajums.REC.93.200 from Vice-Chancellor for Research Affairs of Ahvaz Jundishapur University of Medical Sciences.; therefore, be hereby thank the authorities.

\section{References}

1. Adoukonou T, Houinato D, Kankouan J, et al. Migraine among university students in Cotonou (Benin). Headache. 2009;49:887-893 discussion 894.

2. Moloney MF, Johnson CJ. Migraine headaches: diagnosis and management. $J$ Midwifery Women's Health. 2011;56:282-292.

3. Abel H. Migraine headaches: diagnosis and management. Optometry. 2009;80:138-148.

4. Le H, Tfelt-Hansen P, Skytthe A, Kyvik K, Olesen J. Association between migraine, lifestyle and socioeconomic factors: a population-based crosssectional study. J Headache Pain. 2011;12:157-172.

5. Lipton RB, Stewart WF, Diamond S, Diamond ML, Reed M. Prevalence and burden of migraine in the United States: data from the American migraine study II. Headache. 2001;41:646-657.

6. Victor T, Hu X, Campbell J, Buse D, Lipton R. Migraine prevalence by age and sex in the United States: a life-span study. Cephalalgia. 2010;30:1065-1072.

7. Modara F, Rostam KM. Prevalence of tension and migraine headachesamong the students of Ilam Medical University. J ilam univ med sci. 2008;4:13-21.

8. Parvaz Y, Parvaz P, jahanbaznejad K. A comparative study of personality traits in patients with migraine and controls by personality inventory (MMPI). J Clin Psychol. 2011;1:61-79.

9. Pompili M, Di Cosimo D, Innamorati M, Lester D, Tatarelli R, Martelletti P. Psychiatric comorbidity in patients with chronic daily headache and migraine: a selective overview including personality traits and suicide risk. J Headache Pain. 2009;10:283-290.

10. Nandha R, Chhabra MK. Prevalence and clinical characteristics of headache in dental students of a tertiary care teaching dental hospital in Northern India. Int J Basic Clin Pharmacol. 2013;2:51-55.

11. Al-Hashel JY, Ahmed SF, Alroughani R, Goadsby PJ. Migraine among medical students in Kuwait University. J Headache Pain. 2014;15:26.

12. Ghorbani A, Abtahi S-M, Fereidan-Esfahani M, et al. Prevalence and clinical characteristics of headache among medical students, Isfahan, Iran. J Res Med Sci. 2013;18:S24.

13. Ghorbani A, Abtahi S-M, Fereidan-Esfahani M, et al. Prevalence and clinical characteristics of headache among medical students, Isfahan, Iran. J Res Med Sci. 2013;18:S24-S27.

14. Yousefi M. Prevalence of migraine in medical students and doctors. Zanjan Univ Med Sci J. 2000;8:18-22.

15. Goldberg LD. The cost of migraine and its treatment. Am J Managed Care. 2005; 11:S62-67.

16. Chitsaz A, Ghorbani A. Prevalence of depression and anxiety in patients with migraine and tension headaches, and compared them to those without headache. QJ Fundam Mental Health. 2005;7:41-46.

17. Wang S-J. Epidemiology of migraine and other types of headache in Asia. Curr Neurol Neurosci Rep. 2003:3:104-108.

18. Oztora S, Korkmaz O, Dagdeviren N, et al. Migraine headaches among university students using ID Migraine test as a screening tool. BMC Neurol. 2011;11:103.

19. Behrouz B, Amini K, Abedi A, Ghasemi N. The epidemiology and clinical characteristics of migraine and tension headaches among the patients referred to farabi hospital in Kermanshah city in year. Iran J Epidemiol. 2011;2013 (9):58-65.

20. Semiz M, Şentürk İA, Balaban H, Yağız AK, Kavakçı Ö. Prevalence of migraine and co-morbid psychiatric disorders among students of Cumhuriyet University. J Headache Pain. 2013:14:1-6.

21. Menon B, Kinnera N. Prevalence and characteristics of migraine in medical students and its impact on their daily activities. Ann Indian Acad Neurol. 2013;16:221.

22. Johnson H, Guhl G, Arora J, Walling A. Migraine in students of a US medical school. Fam Med. 2014;46:615-619.

23. Shahrakai MR, Mirshekari H, Ghanbari AT, Shahraki AR, Shahraki E. Prevalence of migraine among medical students in Zahedan faculty of medicine (Southeast of Iran). Basic Clin Neurosci. 2011;2:20-25.

24. Adoukonou T, Houinato D, Kankouan J, et al. Migraine among university students in Cotonou (Benin). Headache. 2009;49:887-893.

25. Mustapha A, Ogunmokun O. The frequency and clinical characteristics of chronic headache among nursing students in a Nigerian University. Neurology. 2012;78: P04. 252.

26. Momayyezi M, Fallahzadeh H, Momayyezi M. Prevalence of migraine and tension-type headache in Yazd (Iran). Zahedan J Res Med Sci. 2014;0.

27. Ojini F, Okubadejo N, Danesi M. Prevalence and clinical characteristics of headache in medical students of the University of Lagos, Nigeria. Cephalalgia. 2009;29:472-477.

28. Christensen AF, Le H, Kirchmann M, Olesen J. Genotype-phenotype correlation in migraine without aura focusing on the rs1835740 variant on 8q22. 1. J Headache Pain. 2012:13:21-27.

29. Khan A, Khattak H, Jamali R, Rashid H, Riaz A, Khan Ibrahimzai A. Prevalence of migraine, its common triggering factors and coping strategies in medica students of Peshawar. Khyber Med Univ J. 2012;4

30. Safavi M, Nazari F, Mahmoudi-Majdabadi M. The relationship of migraine headache and lifestyle among women. Iran J Nurs. 2008;21:89-100.

31. Asadnia S, Sepehrianazar F, Mosarrezaii Aghdam A, Saadatmand S. Comparison of sleep quality and migraine headaches in people with proper and improper and poor sleep. URMIA Med J. 2013;23:799-806. 
32. Seyed Ali M, Taghaddosi M. Relationship between sleep disorders and migraine headaches, nervous. Pajoohandeh J. 2002;7:9-15.

33. MacGregor E, Frith A, Ellis J, Aspinall L, Hackshaw A. Incidence of migraine relative to menstrual cycle phases of rising and falling estrogen. Neurology. 2006;67:2154-2158.

34. Avijgan M. What Is Migraine? What Are the Symptoms and Treatments? What Proportion of People Does It Affect in Australia? Is It More Prevalent Amongst Young People or Old, Women or Men?. Newcastle, NSW, Australia: University of Newcastle; 2011:1-10.
35. Bahrami P, Bayat A. Factors influencing the onset or exacerbation of migraine in 200 patients admitted to the hospital of Khorramabad. Yafte. 2002;4:33-38.

36. Ghasemi $\mathrm{H}$. The effectiveness of diets on migraine headache. Bandar Abbas Univ Med Sci. 2016:56(9):1553-1562.

37. Millichap JG, Yee MM. The diet factor in pediatric and adolescent migraine. Pediatr Neurol. 2003;28:9-15.

38. Taylor FR. Lifestyle changes, dietary restrictions, and nutraceuticals in migraine prevention. Tech Reg Anesthesia Pain Manage. 2009;13:28-37.

39. Mottaghi T, Khorvash F, Askari G, Iraj B, Ghiasvand R. Vitamin D and migraine: review of current evidence. Isfahan Med Sch. 2013;31:32-40. 